\title{
TITULO DEL LIBRO: ILA INEVITABLE GLOBALIZACIÓN. ENFOQUE CULTURAL Y ECONÓMICO DEL ESCENARIO MUNDIAL
}

EDITORIAL: UNIVERSIDAD PERUANA DE CIENCIAS APLICADAS

FECHA DE PUBLICACIÓN: MARZO DE 2017

AUTOR: ÓSCAR SÁNCHEZ BENAVIDES (COMP.)

NÚMERO DE PÁGINAS: 209

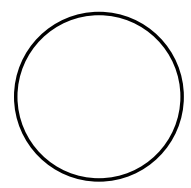

JANNET CANO

El libro, que consta de dos partes, compendia artículos sobre globalización que fueron tomando forma a lo largo de dos años y medio de trabajarse como temas de debate en clases.

En la primera parte, "Rasgos del nuevo entorno económico global", se presentan las definiciones de rigor y el devenir histórico, hasta llegar a la globalización tal como hoy la conocemos, para, desde allí, dar paso a la presentación de tres aspectos económicos que trascienden a la economía mundial: las crisis económicas internacionales desde fines del siglo xx, la trazabilidad para conocer el origen de los productos que compramos y cómo, en el proceso de ampliar su mercado, un emprendedor local pasó del negocio de cabinas de internet a ser un integrador global de tecnologías de la información con plaza en Miami, ampliando sus servicios al desarrollo de proyectos de tecnologías de la información para empresas y gobiernos de diversos países.

En la segunda parte, “Paradojas y trascendencias en una cultura interconectada", se busca reflexionar sobre el paradigma del "choque de civilizaciones" a la luz de los atentados en París, la transformación de una generación a partir de la globalización de la música con el fenómeno de The Beatles, los alcances de la interconexión tecnológica de nuestros tiempos cuestionados en cinco películas, y cómo la globalización ha impactado en un deporte tan popular como el fútbol.

En palabras del compilador, "se trata de artículos que abordan, en un lenguaje sencillo y accesible, diferentes miradas, matizadas por los respectivos perfiles profesionales, de una globalización entendida como un proceso dinámico y en constante cambio, no sin tensiones entre sus protagonistas, algunos de ellos triunfalistas y otros más bien resistentes a dicho proceso. Nuestro libro, al igual que nuestro curso, busca ser una muestra de ese debate permanente" ${ }^{\prime 1}$. Los autores de los artículos son Julio Corcuera Portugal, Jaime Cordero Cabrera, Irma del Águila Peralta, Daniel Flores Bueno, Jorge Illa Boris, Gisella López Lenci, Bruno Rivas Frías y Óscar Sánchez Benavides.
1. La inevitable globalización. Enfoque cultural y económico del escenario mundial (Oscar Sánchez Benavides, compilador). Universidad Peruana de Ciencias Aplicadas (UPC), marzo de 2017, página 17. 